\title{
Interocular transfer of simultaneous but not successive discriminations in the pigeon
}

\author{
LEONARD GREEN \\ Washington University, St. Louis, Missouri 63130 \\ and \\ NICHOLAS BRECHA and MICHAEL S. GAZZANIGA \\ SUNY at Stony Brook, Stony Brook, New York 11790
}

\begin{abstract}
Pigeons were trained with one eye covered on each of two types of visual discriminations. They then were tested for interocular transfer with the previously covered eye. Transfer was shown by every pigeon trained on a simultaneous discrimination, while lack of transfer was shown by these same pigeons when trained on a spatial conditional (successive) discrimination. As opposed to the pigeon, animals with a larger proportion of ipsilateral (uncrossed) retinal fibers (e.g., cats) do show transfer of both discrimination problems. This difference in the decussation of the optic pathways may be a critical variable in interocular transfer in vertebrates. Furthermore, these studies demonstrate that interocular transfer in the pigeon depends upon the experimental paradigm.
\end{abstract}

Although interocular transfer is generally obtained when pigeons are monocularly trained on color, pattern, or brightness discriminations and subsequently tested with the previously occluded eye (Cuénod, 1972; Meier, 1971), the lack of transfer has occasionally been reported. These failures to obtain transfer have been attributed to differences in the region of the pigeon's visual field exposed to the discriminative stimuli, or to the amount of training given on a particular discrimination problem (Catania, 1965; Graves \& Goodale, 1977; Levine, 1945a, 1945b, 1952). The response required of the subject is also considered to be a factor in transfer studies (McCleary, 1960).

The present study, however, demonstrates that whether a pigeon shows transfer or lack of transfer of a discrimination in an appetitive situation depends upon the specific experimental paradigm employed. The lack of transfer cannot be attributed to the placement of the stimuli within the pigeon's visual field, to the choice of response, or to the types of stimuli used.

\section{METHOD}

\section{Subjects}

Eight experimentally naive, White Carneaux pigeons were maintained at $80 \%$ of their free-feeding weights. Water and grit were continuously available in their home cages.

We thank M. Chernoff and L. Griswald for their assistance in running the experiments. The research was supported by a Biomedical Sciences Support Grant, National Institutes of Health, to Leonard Green. Reprints may be obtained from Leonard Green, Departmnt of Psychology, Washington University, St. Louis, Missouri 63130.

\section{Apparatus}

Training and testing took place in a sound-insulated threekey pigeon test chamber (Ralph Gerbrands Co.) measuring $36.2 \mathrm{~cm}$ long $\times 33.7 \mathrm{~cm}$ wide $\times 40.6 \mathrm{~cm}$ high. The grid floor was made of round, stainless steel rods spaced $1.9 \mathrm{~cm}$ apart. Each response key was $2 \mathrm{~cm}$ in diameter and mounted $5 \mathrm{~cm}$ apart on a horizontal plane $21.6 \mathrm{~cm}$ from the grid floor, with the center key located directly above the food hopper. The keys could be transilluminated by colored lights or by white patterns on a black background, and required a force of at least $10 \mathrm{~g}$ $(0.10 \mathrm{~N})$ to operate. Reinforcement consisted of $5 \mathrm{sec}$ access to mixed grain, during which the food hopper (located centrally, $8.9 \mathrm{~cm}$ from the floor) was elevated and lighted by two white bulbs and the response keys were darkened. Time out was a $10-\mathrm{sec}$ period of complete darkness. Two $7-\mathrm{W}$ white bulbs mounted on the ceiling provided general chamber illumination (except during reinforcement or time out). White noise was continuously present, and the programming equipment was located in an adjacent room.

\section{Procedure}

The pigeons were first shaped to peck the center, white response key, and were then fitted with goggles machined from aluminum and built according to the designs of Catania (1963) and Mello (1967). The anterior visual field was exposed through an opening $1.5 \mathrm{~cm}$ in diameter. The goggles eliminated the lateral visual field. An eye was easily occluded by covering the opening of the goggle with an opaque plug. After stable responding was achieved with each eye under alternating monocular discrimination training, interocular transfer tests were begun.

The pigeons were studied daily with one of their eyes covered. Each daily session consisted of 40 trials, with each trial signaled by the illumination of the center, white key. A peck on this key led to its being darkened and the two side keys being immediately illuminated. A response to the correct side key produced $5 \mathrm{sec}$ access to mixed grain, while an incorrect choice led to complete darkening of the chamber for $10 \mathrm{sec}$. After either of these outcomes, the center key was again illuminated, signaling the beginning of the next trial. No correction procedure was used.

Each pigeon was studied both on a simultaneous and on a 
spatial conditional discrimination. The order in which the different problems were presented, as well as which eye was originally covered, was completely counterbalanced among birds. Furthermore, both color and pattern discriminative stimuli wereused in both the simultaneous and the spatial conditional discriminations.

In the simultaneous color discrimination, one of the side keys was illuminated with red light and the other side key with green light. The side on which each of the colors appeared was randomly determined on each trial. A response to the green key, regardless of which side it was on, was defined as correct, while a response to the red key was defined as incorrect. In the simultaneous pattern discrimination, one of the side keys was illuminated by a concentric circle pattern, defined as the correct stimulus, while the other side key was illuminated by a pattern of irradiating lines emanating from a center dot and defined as the incorrect stimulus. The side on which the patterns appeared was also randomly determined on each trial.

In the spatial conditional (successive) discriminations the same colors and patterns as in the simultaneous problems were used. In the color problems, a correct response was defined as a peck on the right key when both were illuminated red and a peck on the left when both were green. For the pattern problems, a right-key response was correct when both keys were illuminated with concentric circles and a left-key response was correct when both keys were illuminated with irradiating lines.

Each pigeon was first monocularly trained on a given discrimination problem until a criterion of 18 correct trials out of 20 for both halves of a daily session, 2 days in a row was attained. On the day following criterion responding, interocular transfer tests were administered to the previously occluded eye. Transfer testing continued until criterion performance with this eye was achieved. After completion of transfer testing, the pigeon was trained on a second discrimination problem with the just-tested eye. As before, after criterion level responding was achieved, transfer tests with the other, occluded eye were then administered. Half the birds were trained and tested with simultaneous color problems and spatial conditional pattern problems, while the other half were trained and tested with simultaneous pattern and spatial conditional color problems.

\section{RESULTS}

Each pigeon demonstrated interocular transfer of the simultaneous discriminations. Figure $1 \mathrm{~A}$ shows that near-perfect performance was shown by the birds on the simultaneous color problem during the first 2 days of transfer testing (mean correct choices was $97 \%$ ). The birds on the simultaneous pattern problem showed somewhat less efficiency but still performed well above chance (mean correct choices was $85 \%$ ). As shown by $t$ tests for nonindepenent samples, there was no significant difference in performance between the final 2 days of discrimination training and the first 2 days of transfer testing for both simultaneous color and pattern problems $(p>.20)$. There was, of course, a highly significant difference in performance between the first 2 days of training when the problem was originally presented and the first 2 days of transfer testing $[\mathrm{t}(3)=5.47$, and $5.91, \mathrm{p}<.02$, for color and pattern, respectively]. These results are similar to those from previous reports on interocular transfer in pigeons trained on a two-choice discrimination (Cuénod, 1972; Meier, 1971).

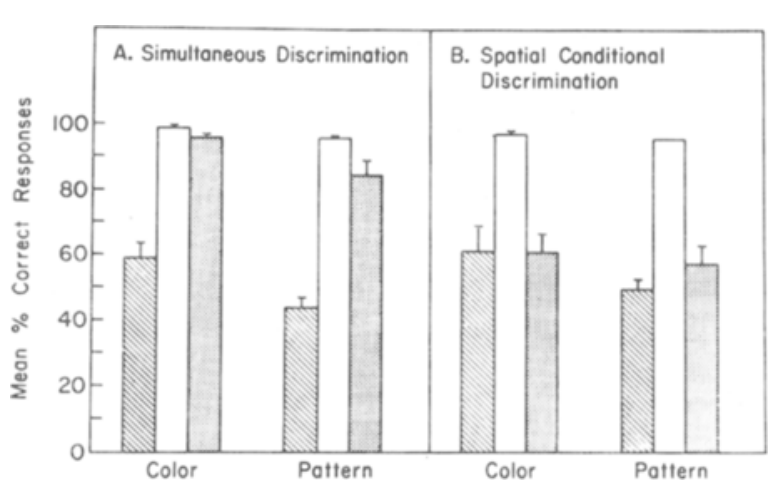

Figure 1. Mean percent correct choices for the simultaneous discriminations (A) and the spatial conditional (successive) discriminations (B) on the first 2 days of discrimination training (cross-hatched bars), the last 2 days of training (criterion performance; open bars), and the first 2 days of interocular transfer tests (dotted bars). The line represents the distance from the mean to +10 .

The excellent performance on the tests for transfer of the simultaneous discriminations stands in marked contrast to that on the conditional problems, as shown in Figure 1B. The mean percent correct responses during the first 2 days of transfer testing was significantly below that of criterion performance [the final 2 days of training; $t(3)=5.75$ and 7.43 , $\mathrm{p}<.02$, for color and pattern, respectively], while not differing from that during the first 2 days when the problem was initially presented to the other eye $(p<.30)$. Thus, there is no evidence for interocular transfer of either the color or the pattern spatial conditional discrimination.

The number of days and the number of errors to criterion in the initial acquisition of each discrimination problem for each pigeon are given in Table 1. While the simultaneous color discrimination was acquired in the fewest days and with the least number of errors, no substantial difference in errors per day is evident among the four problems.

Similar behavioral strategies were employed by the pigeons on both the simultaneous and conditional discriminations when they were first presented. A strong position preference, unrelated to which eye was occluded, predominated early in training. With continued exposure to the problem, such position preferences soon disappeared. When the previously covered eye was tested for interocular transfer, only the birds on the conditional problem again showed any side bias.

\section{DISCUSSION}

Every pigeon tested showed perfect transfer of a simultaneous color discrimination and slightly inferior, although near complete, transfer of the simultaneous pattern discrimination. The color problem, furthermore, was initially acquired in fewer 
Table 1

Number of Days (D) and Errors (E) to Criterion for Each Bird on Each Discrimination Problem

\begin{tabular}{|c|c|c|c|c|c|c|c|c|c|c|c|c|}
\hline & \multicolumn{6}{|c|}{ Color Discriminations } & \multicolumn{6}{|c|}{ Pattern Discriminations } \\
\hline & \multicolumn{3}{|c|}{ Simultaneous } & \multicolumn{3}{|c|}{ Spatial Conditional } & \multicolumn{3}{|c|}{ Simultaneous } & \multicolumn{3}{|c|}{ Spatial Conditional } \\
\hline & $\mathrm{D}$ & E & E/D & $\mathrm{D}$ & E & $E / D$ & $\mathrm{D}$ & $E$ & $\mathrm{E} / \mathrm{D}$ & $\bar{D}$ & $\mathrm{E}$ & $E / D$ \\
\hline & $\begin{array}{l}4 \\
4 \\
3 \\
4\end{array}$ & $\begin{array}{l}23 \\
40 \\
24 \\
44\end{array}$ & $\begin{array}{r}5.8 \\
10.0 \\
8.0 \\
11.0\end{array}$ & $\begin{array}{r}5 \\
21 \\
3 \\
7\end{array}$ & $\begin{array}{r}43 \\
352 \\
15 \\
42\end{array}$ & $\begin{array}{r}8.6 \\
16.8 \\
5.0 \\
6.0\end{array}$ & $\begin{array}{r}6 \\
10 \\
5 \\
9\end{array}$ & $\begin{array}{r}54 \\
141 \\
50 \\
97\end{array}$ & $\begin{array}{r}9.0 \\
14.1 \\
10.0 \\
10.8\end{array}$ & $\begin{array}{r}9 \\
8 \\
14 \\
8\end{array}$ & $\begin{array}{r}114 \\
54 \\
168 \\
97\end{array}$ & $\begin{array}{r}12.7 \\
6.8 \\
12.0 \\
12.1\end{array}$ \\
\hline Median & 4 & 32 & 9.0 & 6 & 42.5 & 7.3 & 7.5 & 75.5 & 10.4 & 8.5 & 105.5 & 12.1 \\
\hline
\end{tabular}

Note-Birds 37, 52, 71, and 76 received the simultaneous color and spatial conditional pattern discriminations. Birds 36, 50, 53, and 60 received the simultaneous pattern and the spatial conditional color discriminations.

days and with fewer errors than was the pattern discrimination. The difficulty of a given discrimination, as reflected in rate of acquisition, appears to affect the extent of interocular transfer in other species as well (e.g., Ingle, 1965; Muntz, 1961; Myers \& Sperry, 1958).

While the difficulty of a discrimination might account for some of the reported failures in transfer studies, difficulty alone cannot account for all of the present results. Specifically, while the spatial conditional color discrimination was, in general, learned faster and with fewer errors than either of the pattern problems, no evidence for interocular transfer on this discrimination problem was obtained. If the difficulty of the discrimination were the only predictor of amount of interocular transfer, then the two color discriminations should have shown the greatest amount of transfer. This was not the case.

In contrast to their performance on both simultaneous discriminations, these same pigeons did not transfer either the color or the pattern spatial conditional (successive) discrimination. The lack of interocular transfer with the spatial conditional discriminations cannot be accounted for on the basis of differential stimulation of the pigeons visual field, since the placement of the goggles permitted only anterior field stimulation for both types of discrimination paradigms. The location of the stimuli within the operant chamber, as well as the actual stimuli used, were the same for each discrimination problem. Furthermore, the procedure required the same type of response for both problems, namely left and right keypecks, so that the nature of the response, per se, was not an important variable.

With the elimination of these factors, the present data suggest that interocular transfer is influenced by the specific experimental paradigm employed. The same pigeon which demonstrates complete transfer of a simultaneous discrimination shows no transfer of a spatial conditional discrimination. The possible anatomical or physiological bases for these results are, at present, unknown. However, there appears to be an interesting correlation in vertebrates between the amount of crossed and uncrossed retinal projections with the efficiency and extent of interocular transfer (see, e.g., Cowey \& Parkinson, 1973; Ingle, 1965; Van Hof, 1970). This difference in the decussation of the optic pathways may be relevant since other work from our laboratories has shown a lack of interocular transfer using our spatial conditional discrimination problem in the goldfish which, like the pigeon, has a seemingly completely crossed retinal system (Cowan, Adamson, \& Powell, 1961; Sharma, 1972) and good interocular transfer in the normal and chiasm-sectioned cat. Finally, these results point up the importance of a comparative approach to the study of brain and behavior.

\section{REFERENCES}

Catania, A. C. Techniques for the control of monocular and binocular viewing in the pigeon. Journal of the Experimental Analysis of Behavior, 1963, 6, 627-629.

Catania. A. C. Interocular transfer of discriminations in the pigeon. Journal of the Experimental Analysis of Behavior, 1965. 8, 147-155.

Cowan, W. M., Adamson, L., \& Powell, T. P. S. An experimental study of the avian visual system. Journal of A natomy, $1961,95,545-562$.

Cowey, A., \& Parkinson, A. M. Effects of sectioning the corpus callosum on interocular transfer in hooded rats. Experimental Brain Research, 1973, 18, 433-445.

Cú́NoD, M. Split-brain studies. Functional interaction between bilateral central nervous structures. In G. H. Bourne (Ed.), The structure and function of nervous tissue (Vol. 5). New York: Academic Press, 1972.

Graves, J. A., \& Goodale. M. A. Failure of interocular transfer in the pigeon (Columba livia). Physiology \& Behavior, 1977. $19,425-428$.

INGLE, D. J. Interocular transfer in goldfish: Color easier than pattern. Science, 1965, 149, 1000-1002.

Levine, J. Studies in interrelations of central nervous structures in binocular vision. 1. The lack of bilateral transfer of visual discriminative habits acquired monocularly by the pigeon. Journal of Genetic Psychology, 1945, 67, 105-129. (a)

LEVINE, J. Studies in the inter relations of central nervous structures in binocular vision: II. The conditions under which interocular transfer of discriminative habits takes place in the pigeon. Journal of Genetic Psychology, 1945, 67, 131-142. (b) 
LEviNe, J. Studies in the interrelations of central nervous structures in binocular vision: III. Localization of the memory trace as evidenced by the lack of inter- and intraocular habit transfer in the pigeon. Journal of Genetic Psychology, 1952, 81, 19-27.

McCleary, R. A. Type of response as a factor in interocular transfer in the fish. Journal of Comparative and Physiological Psychology, 1960, 53, 311-321.

MEIER, R. E. Interhemisphärischer transfer visueller Zweifachwahlen bei kommissurotomierten Tauben. Psychologische Forschung, 1971, 34, 220-245.

Mello, N. K. A method for restricting stimuli to the frontal or lateral visual field of each eye separately in pigeon. Psychonomic Science, 1967, 8, 15-16.
Muntz, W. R. A. Interocular transfer in Octopus vulgaris. Journal of Comparative and Phvsiological Psychology, 1961, 54, 49-55.

MYers, R. E., \& SPERry, R. W. Interhemispheric communication through the corpus callosum: Mnemonic carry-over between the hemispheres. Archives of Neurological Psychiatry, 1958, 80, 298-303.

Sharma, S. C. The retinal projections in the goldfish: An experimental study. Brain Research, 1972, 39, 213-223.

VAN Hof, M. W. Interocular transfer in the rabbit. Experimental Neurology, 1970, 26, 103-108.

(Received for publication January 3, 1978; revision accepted March 27, 1978.) 